\title{
Gastric Cardia
}

National Cancer Institute

\section{Source}

National Cancer Institute. Gastric Cardia. NCI Thesaurus. Code C12256.

The area around the esophag og astric mucosal junction where the esophageal mucosa transitions into the gastric mucosa. 